\title{
REMOÇÃO DE CORANTE POR USO DE Aspergillus niger AN400 EM REATOR EM BATELADAS SEQUENCIAIS
}

\author{
Kelly Rodrigues*, Karla Mayara Lima da Silva, Glória Maria Marinho Silva e Paulo Cesar Cunha Lima \\ Instituto Federal de Educação Ciência e Tecnologia do Ceará, Campus Fortaleza, Av. Treze de Maio, 2081, 60040-531 Fortaleza \\ - CE, Brasil \\ Carlos Ronald Pessoa Wanderley e Germana Marinho Silva \\ Instituto Federal de Educação Ciência e Tecnologia do Ceará, Campus Maracanaú, Av. do Contorno Norte, 61936-000 Maracanaú \\ $-\mathrm{CE}$, Brasil
}

Recebido em 28/5/10; aceito em 25/1/11; publicado na web em 1/4/11

\begin{abstract}
DYE REMOVAL BY USE OF Aspergillus niger AN 400 IN A SEQUENTIAL BATCH REACTOR. A sequential batch reactor (4 L) inoculated with Aspergillus niger was operated in order to remove congo red dye $\left(10 \mathrm{mg} \mathrm{L}^{-1}\right)$. The feeding of the reactor was done to

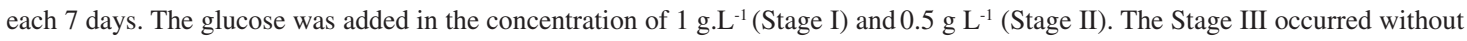
glucose addition. The Stage I was great to process, because the system reached the greater dye removal (95\%) as well as the kinetic parameters ware the best $-\mathrm{K}_{\mathrm{M}}\left(0.7 \mathrm{~g} \mathrm{~L}^{-1}\right)$ and $k_{1}\left(0.025 \mathrm{~h}^{-1}\right)$.
\end{abstract}

Keywords: Aspergillus niger; sequential batch; congo red.

\section{INTRODUÇÃO}

Os corantes sintéticos do tipo azo $(-\mathrm{N}=\mathrm{N}-)$ representam cerca de $70 \%$ do mercado mundial de corantes, sendo estimada a perda em cerca de 10 a $20 \%$ de sua massa, principalmente nas etapas secundárias de beneficiamento têxtil, ${ }^{1,2}$ o que resulta em preocupação ambiental quando do descarte inadequado dos efluentes têxteis, pois estes corantes possuem como característica a persistência no meio ambiente. ${ }^{3}$

A presença de corantes têxteis em corpos hídricos receptores predispõe à toxicidade a vida aquática e diminui a transparência de água, afetando o processo de fotossíntese e a concentração de oxigênio dissolvido que é essencial à biota. ${ }^{3,4}$

Vários processos físico-químicos têm sido utilizados visando o tratamento destes despejos - coagulação, seguida de flotação ou sedimentação, adsorção em carvão ativado, ${ }^{5}$ processos oxidativos avançados, ${ }^{6,7}$ sistemas eletroquímicos ${ }^{8}$ entre outros. Porém, esses processos apresentam custo elevado e baixa eficiência para remoção de cor e matéria orgânica dissolvida, além de não serem destrutivos, o que faz com que a disposição da fase sólida se constitua em outro aspecto negativo do tratamento físico-químico. ${ }^{7-9}$

Em relação aos processos biológicos, os sistemas anaeróbios e aeróbios - fundamentados na ação de bactérias - podem alcançar bons níveis de eficiência quando utilizados em conjunto, mas, separadamente, não apresentam percentuais de remoção satisfatórios. ${ }^{10,11} \mathrm{Em}$ ambiente anaeróbio, a partir da clivagem da molécula do corante, são formadas aminas aromáticas cancerígenas, que são ainda mais difíceis de serem degradadas, exigindo o pós-tratamento do efluente em unidades aeróbias, ${ }^{12,13}$ como, por exemplo, o sistema de lodos ativados, que é muito empregado para o pós-tratamento desses efluentes. Mas esse sistema, apesar dos bons resultados em relação à remoção de cor, apresenta produção de lodos elevada e é susceptível a choques de carga orgânica. ${ }^{14,15}$

*e-mail: kelly@ifce.edu.br
Apesar de recente, em comparação com outros sistemas biológicos, a utilização de fungos na biorremediação de poluentes tem sido relatada na literatura especializada devido ao potencial enzimático desses micro-organismos. ${ }^{16}$

As espécies de Aspergillus são conhecidas por sua capacidade de utilizar de corantes como substrato, transformando-os em compostos não tóxicos ou de baixa toxicidade,,${ }^{17,18}$ o que ocorre pela produção de enzimas extracelulares, as quais tornam o organopoluente acessível para assimilação. ${ }^{16} \mathrm{~A}$ espécie Aspergillus niger, em função das condições do meio, é capaz de produzir mais de 19 enzimas diferentes, tais como celulases, peroxidases, lactases, lacases e amilases. ${ }^{19,20}$

$\mathrm{O}$ uso de reatores com fungos para o tratamento de despejos industriais pode vir a ser uma tecnologia econômica e eficiente. Entretanto, um dos maiores problemas para a sua viabilidade é a falta de consenso sobre as condições operacionais ótimas, em busca da completa mineralização do poluente, o que pode variar em função do substrato e da espécie utilizada. ${ }^{19}$

Desta forma, há a necessidade de se estudar a otimização do processo de degradação de corantes por Aspergillus niger, bem como por outras espécies de fungos, geneticamente modificadas ou não, haja vista o potencial reconhecido destes micro-organismos na biorremediação de corantes têxteis e de muitos outros compostos.

Durante a operação de reatores com fungos são observados alguns problemas como crescimento excessivo da biomassa, limitação difusional e perda da eficiência do tratamento de efluentes de complexidade elevada. ${ }^{21}$

Sobre esse aspecto, exige-se que todas as variáveis envolvidas no processo de micorremediação sejam investigadas, a fim de que os reatores com inóculo fúngico, quando da operação em macroescala, venham a ser viáveis e possam ser estabelecidos competitivamente no processamento eficiente dos grandes volumes dos despejos gerados.

Podem-se citar como alvo de estudo desse processo: o tempo reacional e o tempo de detenção hidráulica, respectivamente, para reatores em batelada e os de escoamento contínuo; o uso de espécies geneticamente modificadas visando o maior rendimento do processo; a influência do tipo da concentração de cossubstrato sobre a velo- 
cidade da degradação do poluente e a eficiência global e o nível de mineralização do poluente, entre outras. ${ }^{16,21,22}$

Dentro deste contexto, a adição de cossubstrato é de grande importância, pois pode contribuir para maiores eficiências de remoção dos corante e de seus intermediários, devido à formação de compostos altamente reativos pela adição de glicose, os quais podem melhorar a assimilação dos poluentes pelos fungos e diminuir a toxicidade do meio. ${ }^{22}$

Assim, considerando o uso de um reator em bateladas sequenciais, inoculado com biomassa imobilizada de Aspergillus niger AN400, de linhagem fúngica geneticamente modificada, não produtora de antígenos, e com capacidade para produção de ácidos orgânicos a partir de substratos variados, o presente trabalho teve por objetivo avaliar o tratamento de meio sintético contendo corante vermelho do congo.

\section{PARTE EXPERIMENTAL}

\section{Inóculo}

A linhagem Aspergillus niger AN400 foi desenvolvida no Departamento de Genoma de Fungos da Universidade de Wageningen, na Holanda. De saída, encontrava-se na forma de esporos, armazenada em tubo de ensaio $(10 \mathrm{~mL})$, mantido a $\pm 4{ }^{\circ} \mathrm{C}$, depois submetida a um descongelado à temperatura ambiente para produção de maior quantidade de suspensão de esporos.

O cultivo dos fungos foi feito em 8 placas de Petri que foram preenchidas com $20 \mathrm{~mL}$ de meio cultura Saboraud Dextrose e, após solidificação do meio, uma alça estéril de platina foi imersa no frasco que continha a solução de esporos original e a amostra retirada foi repicada no centro das placas. Todos os procedimentos de cultivo e repicagem ocorreram na proximidade de bico de Bunsen.

Em seguida, as placas foram incubadas em estufa bacteriológica a uma temperatura de $\pm 30{ }^{\circ} \mathrm{C}$, onde permaneceram durante 5 dias para crescimento dos esporos. Após esse período, os esporos foram removidos das placas com auxílio de alça de Drigalsky e de solução Tween 80 e transferidos para recipiente de armazenamento.

A contagem do número de esporos presentes na suspensão foi realizada em microscópio óptico, aumento de 400 vezes, com ajuda de câmara de Neubauer.

\section{Meio basal}

O meio foi preparado com água da torneira, acrescida de (mg $\left.\mathrm{L}^{-1}\right):\left(\mathrm{NH}_{4}\right)_{2} \mathrm{SO}_{4}(500), \mathrm{NaNO}_{3}(250), \mathrm{K}_{2} \mathrm{HPO}_{4}(200), \mathrm{MgSO}_{4} \cdot 7 \mathrm{H}_{2} \mathrm{O}$ (250) e $\mathrm{CaCl}_{2} \cdot 2 \mathrm{H}_{2} \mathrm{O}(10), \mathrm{CuSO}_{4} \cdot 7 \mathrm{H}_{2} \mathrm{O}(80), \mathrm{H}_{2} \mathrm{MoO}_{4}(50), \mathrm{MnSO}_{4}$. $5 \mathrm{H}_{2} \mathrm{O}(50), \mathrm{Fe}_{2}\left(\mathrm{SO}_{4}\right)_{3}(50), \mathrm{ZnSO}_{4}(40)$.

\section{Reator em bateladas sequenciais com biomassa imobilizada (RBBI)}

\section{Imobilização da biomassa}

A espécie mutante Aspergillus niger AN400 foi imobilizada em espuma de poliuretano cortada em cubos de $1 \mathrm{~cm}$ de aresta, previamente esterilizada a $\pm 121^{\circ} \mathrm{C}$ por 20 min.

Para o procedimento de imobilização, frascos (erlenmayer) de $250 \mathrm{~mL}$ receberam adição de $150 \mathrm{~mL}$ de meio basal descrito anteriormente, $5 \mathrm{~g} \mathrm{~L}^{-1}$ de glicose e de inóculo, na concentração de $2 \mathrm{x}$ $10^{6}$ esporos $\mathrm{mL}^{-1}$.

Os erlenmayers foram mantidos em mesa agitadora horizontal, sob agitação orbital de $150 \mathrm{rpm}$ e temperatura de $\pm 28^{\circ} \mathrm{C}$, durante $72 \mathrm{~h}$. Ao completar $24 \mathrm{~h}$, o meio antigo foi substituído por um novo de mesma composição, permanecendo nesta condição por mais $72 \mathrm{~h}$.
Ao fim desse tempo, as espumas que continham a biomassa fúngica aderida à sua superfície foram lavadas com água destilada e transferidas para o reator em batelada para o início da operação do mesmo.

\section{Montagem e operação do reator}

O reator de batelada sequencial era de vidro e possuía volume total de 5 L. Sua alimentação foi feita com o meio basal, contendo $10 \mathrm{mg}$ $\mathrm{L}^{-1}$ do corante vermelho do congo, além de glicose cuja concentração variou em função da etapa operacional (Etapas I, II e III), conforme apresentado na Tabela 1 .

Tabela 1. Distribuição dos ciclos de operação do reator em regime de batelada sequencial, em função da concentração da glicose

\begin{tabular}{cccc}
\hline Etapa & Ciclo & $\begin{array}{c}\text { Glicose } \\
\left(\mathrm{g} \mathrm{L}^{-1}\right)\end{array}$ & $\begin{array}{c}\text { Tempos de reação } \\
\text { estudados (dias) }\end{array}$ \\
\hline I & 1 & 1,0 & $1,2,3,4,5,6$ e 7 \\
II & 2 & & \\
& 3 & 0,5 & $1,2,3,4,5,6$ e 7 \\
& 1 & & \\
III & 3 & & $1,2,3,4,5,6$ e 7 \\
& 1 & & \\
& 2 & & \\
\hline
\end{tabular}

Cada etapa era compreendida de três ciclos operacionais e em cada um dos ciclos o reator foi alimentado com $4 \mathrm{~L}$ do meio, com retirada de alíquota a cada $24 \mathrm{~h}$ para monitoramento, sendo o tempo reacional total de 7 dias.

O volume amostral retirado para a realização das análises foi de apenas $10 \%$ do volume útil do reator por ciclo estudado. $\mathrm{O}$ ar foi fornecido por minicompressor e difundido no meio por pedra porosa. O reator foi coberto com sacos pretos de polietileno, a fim de evitar a possibilidade de ocorrer fotodegradação pela ação da luz ambiente.

Foram realizadas as análises de corante, de matéria orgânica dissolvida - em termos de DQO - e $\mathrm{pH}$, segundo os procedimentos descritos em APHA, ${ }^{23}$ exceto a de corante.

A determinação da concentração de corante ocorreu por método espectrofotométrico. Estabeleceu-se a relação entre a absorbância e o equivalente em termos de concentração de corante e construiu-se a curva de calibração.

Para a curva de calibração foram utilizadas soluções de concentrações conhecidas de vermelho do congo, variando de 0 (branco) a $15 \mathrm{mg} \mathrm{L}^{-1}$, sendo que, antes da leitura em comprimento de onda $(\lambda)$ de $500 \mathrm{~nm}$, as amostras foram centrifugadas a $3500 \mathrm{rpm}$, durante $15 \mathrm{~min}$.

A partir dos dados de absorbância versus concentração de corante adicionado, foi obtida a equação que estabeleceu a relação entre concentração de corante equivalente e absorbância.

\section{Análises microscópicas}

Foram retiradas amostras do biofilme para realização de exames microscópicos, no final da operação do reator.

$\mathrm{O}$ biofilme aderido à manta suporte foi removido com ajuda de pérolas de vidro e água destilada esterilizada a $121^{\circ} \mathrm{C}$ a $1 \mathrm{~atm}$. Posteriormente, foram feitas diluições de $10^{-1}, 10^{-2}$ e $10^{-3} \mathrm{e}$, em seguida, foi retirado $1 \mathrm{~mL}$ de cada diluição para adição em placas de Petri que continham $20 \mathrm{~mL}$ de meio Saboraud, sendo ao todo 9 placas -3 placas para cada diluição - que foram mantidas em estufa a $\pm 30{ }^{\circ} \mathrm{C}$ por 7 dias, para verificação das colônias. 
Amostras das placas que receberam as diluições foram fixadas em lâminas com ágar, realizando-se, em seguida, a microscopia em microscópio óptico Acrom L1000, com aumento de até 1600 vezes a fim de identificar com base nas estruturas morfológicas os microorganismos presentes no reator.

\section{Contagem dos micro-organismos em placas}

A contagem e o plaqueamento de micro-organismos foram feitos com procedimento de diluição em série, com uso do meio seletivo de Martin para fungos, o qual foi preparado com $1000 \mathrm{~mL}$ de água destilada e os seguintes constituintes $\left(\mathrm{g} \mathrm{L}^{-1}\right)$ : $\mathrm{K}_{2} \mathrm{HPO}_{4}(1)$; peptona (5); $\mathrm{KH}_{2} \mathrm{PO}_{4}(5) ; \mathrm{MgSO}_{4} .7 \mathrm{H}_{2} \mathrm{O}(0,5)$; dextrose (10); extrato de levedura $(0,5)$; rosa bengala $(0,033)$ e ágar $(18)$. O antibiótico estreptomicina $\left(3 \mu \mathrm{g} \mathrm{mL} \mathrm{m}^{-1}\right)$ foi adicionado ao meio para evitar contaminação por bactérias.

Foram retiradas amostras de $10 \mathrm{~mL}$ do conteúdo líquido do reator em operação no último ciclo operacional da Etapa II, misturando-se as mesmas a $90 \mathrm{~mL}$ de solução salina $(0,89 \%)$ em tubo de ensaio de $20 \mathrm{~mL}$, que foi submetido à agitação em vórtex, durante $10 \mathrm{~min}$.

Em seguida, alíquotas de $1 \mathrm{~mL}$ foram transferidas para um novo tubo de ensaio, contendo $9 \mathrm{~mL}$ da solução salina e, após agitação manual, procedeu-se assim sucessivamente de forma a se obterem concentrações de $10^{-2}, 10^{-3}$ e $10^{-4}$. Alíquotas de $0,1 \mathrm{~mL}$ foram retiradas de cada uma destas diluições e adicionadas às placas contendo o meio Martin, de que foram obtidas concentrações de respectivamente de $10^{-3}, 10^{-4}$ e $10^{-5}$.

Para promover o espalhamento das colônias na superfície das placas, foi utilizada alça de Drigalski. Posteriormente, as placas foram vedadas e incubadas à temperatura de $28^{\circ} \mathrm{C}$ durante 5 dias para permitir o crescimento das colônias fúngicas.

A contagem foi realizada pela identificação visual de pontos de colônias de fungos, formados nas placas, após o período de incubação. O número de colônias foi multiplicado pelas diluições correspondentes à cada placa.

\section{Ensaio de adsorção no micélio morto}

Para o ensaio de adsorção do corante vermelho do congo, utilizouse $0,9 \mathrm{~g}$ de biomassa morta de Aspergillus niger AN400.

Primeiramente, foi realizado o ensaio com biomassa morta, que foi produzida a partir do cultivo de biomassa com adição de $2 \times 10^{6}$ esporos $/ \mathrm{mL}$ e de $5 \mathrm{~g} \mathrm{~L}^{-1}$ de glicose em três erlenmeyer de $250 \mathrm{~mL}$, contendo cada um $200 \mathrm{~mL}$ do meio basal, descrito anteriormente, tendo sido o mesmo previamente esterilizado a $121^{\circ} \mathrm{C}$, durante $20 \mathrm{~min}$. Todo procedimento foi realizado em uma câmara de fluxo laminar.

Os erlenmeyers foram postos sob agitação em uma incubadora de bancada para crescimento da espécie fúngica a $125 \mathrm{rpm}$ e temperatura de $29,6{ }^{\circ} \mathrm{C}$, durante 7 dias, para crescimento da espécie.
Após esse período, a massa fúngica produzida foi morta por autoclavagem a $121^{\circ} \mathrm{C}$, durante $30 \mathrm{~min}$. A biomassa foi então lavada e ainda filtrada em sistema de filtração a vácuo, para retirada de umidade, permanecendo em estufa, a $\pm 55^{\circ} \mathrm{C}$, até obtenção do peso seco.

Para o ensaio de adsorção a biomassa morta de Aspergillus niger NA 400 foi introduzida em erlenmayer de $250 \mathrm{~mL}$, com volume reacional de $200 \mathrm{~mL}$ e $0,4 \mathrm{~g} \mathrm{~L}^{-1}$ de vermelho do congo. O monitoramento da concentração do corante adsorvido na biomassa morta foi realizado com base na medida da sua concentração no meio, com leituras em intervalos de $30 \mathrm{~min}$, até se atingir a saturação da mesma e se obter a massa total de corante, bem como a capacidade de adsorção do micélio.

\section{Ensaio de adsorção no material suporte}

Foram utilizados $5 \mathrm{~g}$ de cubos de espuma de poliuretano previamente secos em estufa $\mathrm{a} \pm 55^{\circ} \mathrm{C}$. Os cubos foram adicionados em erlenmayer de $250 \mathrm{~mL}$, que receberam $200 \mathrm{~mL}$ do meio basal acrescido de $0,4 \mathrm{~g} \mathrm{~L}^{-1}$ de vermelho do congo.

A capacidade máxima de adsorção do corante na espuma de poliuretano empregada como material suporte foi feita de modo similar ao ensaio de adsorção com o micélio morto.

\section{RESULTADOS E DISCUSSÃO}

Na Tabela 2 são apresentadas as características do meio utilizado para alimentação do reator em bateladas sequenciais, nas Etapas I, II e II.

A concentração média inicial de corante no meio foi de $10 \pm 3$ $\mathrm{mg} \mathrm{L}^{-1} \mathrm{e}$ os valores iniciais de $\mathrm{pH}$ foram característicos de meio ácido, de 5,6; 3,7 e 4,3, respectivamente, nas Etapas I, II e III. Estes valores são benéficos aos fungos, que possuem grande capacidade metabólica em meios ácidos. ${ }^{24}$ Além disso, o pH baixo se constituiu em um fator minimizador da atividade de eventuais bactérias contaminantes. ${ }^{16}$

Em relação às etapas estudadas, verificou-se que os melhores resultados foram alcançados com a adição de $1 \mathrm{~g} \mathrm{~L}^{-1}$ de glicose (Etapa I), quando foi registrada eficiência média de remoção de corante de $95 \%$, sendo que o percentual máximo de remoção foi obtido ainda no primeiro ciclo (96\%), no tempo reacional de $168 \mathrm{~h}$.

Nas Etapas II e III, os percentuais de remoção do corante foram, respectivamente, de 90 e $89 \%$, indicando que a adição de glicose, na concentração de $0,5 \mathrm{~g} \mathrm{~L}^{-1}$, não apresentou resultados muito diferentes da situação em que a mesma não foi adicionada no meio, o que foi endossado pelo coeficiente de velocidade $(k)$ - considerando a reação de primeira ordem, de acordo com a Equação $1-$, de $0,01 \mathrm{~h}^{-1}$, em ambas as etapas.

$$
\ln \frac{C}{C o}=-k_{1} \cdot \Delta t
$$

Tabela 2. Características do meio basal contendo o corante vermelho do congo nas Etapas I, II e III de operação do reator em batelada sequencial

\begin{tabular}{|c|c|c|c|c|c|c|}
\hline \multirow{2}{*}{ Variável } & \multicolumn{6}{|c|}{ ETAPA } \\
\hline & I & DP & II & DP & III & DP \\
\hline $\mathrm{pH}$ & 4,1 & $\pm 0,3$ & 4,0 & $\pm 0,5$ & 4,0 & $\pm 0,5$ \\
\hline Corante $\left(\mathrm{mg} \mathrm{L}^{-1}\right)$ & 8 & $\pm 1,5$ & 10 & $\pm 2,5$ & 11,0 & \pm 5 \\
\hline DQO dissolvida $\left(\mathrm{mg} \mathrm{L}^{-1}\right)$ & 1034 & \pm 130 & 423 & \pm 239 & 51 & \pm 10 \\
\hline Amônia total $\left(\mathrm{mg} \mathrm{L}^{-1}\right)$ & 711 & \pm 28 & 758 & \pm 48 & 638 & \pm 33 \\
\hline Nitrito $\left(\mathrm{mg} \mathrm{L}^{-1}\right)$ & 0,034 & $\pm 0,01$ & 0,17 & $\pm 0,20$ & 0,07 & $\pm 0,04$ \\
\hline Nitrato $\left(\mathrm{mg} \mathrm{L}^{-1}\right)$ & 2 & \pm 1 & 5 & $\pm 2,5$ & 7 & $\pm 3,4$ \\
\hline Ortofosfato (mg L $\left.\mathrm{m}^{-1}\right)$ & 955 & \pm 197 & 943 & \pm 212 & 1034 & \pm 80 \\
\hline
\end{tabular}


sendo $\mathrm{C}$ a concentração do corante no tempo t; Co a concentração inicial do corante; $k_{1}$, constante de velocidade e $\Delta \mathrm{t}$, a variação entre o tempo inicial e final.

Em contrapartida, o coeficiente de velocidade $\left(k_{1}\right)$, registrado na Etapa I foi de $0,025 \mathrm{~h}^{-1}$. Este valor foi cerca de 2,5 vezes superior ao encontrado nas Etapas II e III, mostrando que a concentração de $1 \mathrm{~g}$ $\mathrm{L}^{-1}$ de glicose proporcionou maior eficiência para o processo.

Na Tabela 3 são mostrados os valores médios para a constante de velocidade $\left(k_{1}\right)$ e para o coeficiente $\mathrm{R}^{2}$, obtidos nas etapas de estudo, em relação ao consumo de vermelho do congo e de matéria orgânica.

Tabela 3. Valores médios de $\mathrm{k}_{1}$ e de $\mathrm{r}^{2}$ para o corante vermelho do congo e de matéria orgânica, obtidos nas Etapas I, II e III

\begin{tabular}{lllcc}
\hline Variável & & \multicolumn{3}{c}{ ETAPA } \\
\cline { 3 - 5 } & & \multicolumn{1}{c}{$\mathrm{I}$} & $\mathrm{II}$ & $\mathrm{III}$ \\
\hline Corante & $k_{1}\left(\mathrm{~h}^{-1}\right)$ & 0,025 & 0,01 & 0,01 \\
& $\mathrm{R}^{2}$ & 0,847 & 0,876 & 0,953 \\
\multirow{2}{*}{ Matéria orgânica } & $k_{1}\left(\mathrm{~h}^{-1}\right)$ & 0,048 & 0,015 & 0,015 \\
& $\mathrm{R}^{2}$ & 0,882 & 0,816 & 0,905 \\
\hline
\end{tabular}

Há relatos do aumento da eficiência para a remoção de cor pela adição da glicose em meios contendo os mais diversos corantes. ${ }^{22,25-27}$ Porém, a maioria dos fungos, na ausência de cossubstrato, como a glicose, não consegue utilizar corantes têxteis em seu metabolismo, necessitando da presença de fonte de carbono de fácil assimilação. ${ }^{22,28}$

A glicose é o substrato de mais fácil assimilação, sendo exaurida muito rapidamente do meio. Frequentemente, em 2 dias, nos reatores de baletada operados a uma concentração inicial de $5 \mathrm{~g} \mathrm{~L}^{-1}{ }^{16}$ favorecendo o crescimento dos fungos e a produção de enzimas extracelulares. ${ }^{22}$

Entretanto, a concentração ótima do cossubstrato a ser empregada depende da espécie fúngica, da estrutura molecular do corante, do regime de operação do reator e da idade do biofilme, entre outros fatores. Seu excesso no meio, porém, pode acarretar a repressão do sistema enzimático e da utilização do substrato. ${ }^{22}$

Ali et al. ${ }^{29}$ verificaram que a partir de $10 \mathrm{~g} \mathrm{~L}^{-1}$ de glicose, o efeito indutor desta foi revertido, de modo que Aspergillus niger não conseguiu eficiente remoção da cor de meio que continha $20 \mathrm{mg} \mathrm{L}^{-1}$ do corante diazo vermelho ácido 151 , obtendo remoção de apenas 33,2\%, em tempo reacional de 8 dias. Por outro lado, ao se adicionar $5 \mathrm{~g} \mathrm{~L}^{-1} \mathrm{de}$ glicose, os autores obtiveram aumento da eficiência para 77\%, mostrando a importância da concentração do cossubstrato para a eficiência do sistema, uma vez que o mesmo se constitui em um indutor enzimático. ${ }^{22}$

Nesta pesquisa, a adição de $1 \mathrm{~g} \mathrm{~L}^{-1}$ de glicose não foi suficiente para prover a utilização efetiva do benzeno, embora tenha contribuído para a ruptura dos grupos cromóforo da ligação azo $(\lambda: 500 \mathrm{~nm})$ e do naftaleno $(\lambda: 310 \mathrm{~nm})$ - não detectados no efluente -, tendo-se obtido diminuição pequena, $30 \%$ do valor relativo à sua absorbância no comprimento de onda $(\lambda)$ de $233 \mathrm{~nm}$.

Os fungos atuam sobre o corante a partir da ação de enzimas como peroxidases e fenoloxidases por eles produzidas, as quais contribuem para a clivagem assimétrica da ligação azo, formando quinonas e derivados do diazeno, além de ocorrer liberação de nitrogênio. ${ }^{28}$ É relatada a produção de metabólitos diversos na biodegradação de corantes azo, inclusive, muitos destes ainda não foram identificados, mas observada a produção de ácido hidroxibenzoico, álcool $m$-benzyl, acetanilida, entre outros. ${ }^{22}$

A desestabilização do benzeno, por sua vez, apresenta maior grau de complexidade, pois o anel sozinho é muito estável e, para sua clivagem, é necessária maior reatividade dessa molécula, o que pode ser obtido com o aumento da glicose no meio até a concentração ótima para a indução enzimática, visto que sua presença resulta na formação de compostos altamente reativos que facilmente se envolvem em reações secundárias com compostos mais persistentes como o benzeno, aumentando a capacidade de mineralização do sistema. ${ }^{22,30}$

$\mathrm{Na}$ presente pesquisa, quanto à influência do material suporte e à do próprio micélio fúngico de adsorver o corante, os ensaios de adorção realizados mostraram que os mesmos tiveram pouca influência na remoção do corante. A capacidade máxima do material suporte e a do micélio morto em adsorver o vermelho do congo era de, respectivamente, 0,005 g de corante/g de espuma e de 0,06 g de corante/g de micélio.

O sistema removeu 0,08 g de corante por grama de espuma, o equivalente a uma massa 4 e 3 vezes maior que a retida pelo material suporte no ponto de saturação da espuma suporte e que a do micélio morto, respectivamente, considerando que havia ao final do experimento $0,50 \mathrm{~g}$ de biomassa no interior do reator, crescendo aderida ao material suporte.

Mesmo no primeiro ciclo da Etapa I, no qual foram observadas as maiores remoções de corante e a ação da adsorção poderia ser maior, em virtude da disponibilidade elevada de sítios de ligação no material suporte, houve remoção de $0,008 \mathrm{~g}$ de corante por grama de espuma, o que equivale à remoção de 1,6 vezes a massa de corante que a espuma de poliuretano é capaz de adsorver.

Na Etapa I foram também registradas as melhores remoções de matéria orgânica carbonácea, medida em termos de DQO. O maior percentual de remoção de matéria orgânica ocorreu no tempo reacional de 96 h do primeiro ciclo (99\%) e a remoção média de matéria orgânica foi de $86 \%$, obtendo-se coeficiente de velocidade $k_{1}$ de $0,048 \mathrm{~h}^{-1}$.

Ainda nesta pesquisa, os resultados estimados para a constante cinética de Michaelis-Menten $\left(\mathrm{K}_{\mathrm{M}}\right)$ pelo ajuste dos dados de decaimento de corante na equação linearizada de Hanes Woolf (Equação 2), ratificaram o alcance da melhor eficiência do tratamento na Etapa I, para a qual foi encontrado o valor mais baixo de $\mathrm{K}_{\mathrm{M}}$, de $0,7 \mathrm{~g} \mathrm{~L}^{-1}$ $\left(\mathrm{r}^{2}: 0,871\right)$, indicando que a glicose, adicionada na concentração de $1 \mathrm{~g} \mathrm{~L}^{-1}$, foi melhor para o processo.

$$
\frac{C_{S}}{r}=\frac{K_{M}}{r_{\max }}+\frac{1}{r_{\text {max }}} C_{S}
$$

sendo $\mathrm{C}_{\mathrm{S}}$ a concentração do corante; $K_{\mathrm{M}}$ a constante de MichaelisMenten ou de afinidade pelo substrato; $r$ a velocidade de remoção do corante e $r_{\text {máx }}$ a velocidade máxima de remoção do corante.

Ao diminuir a concentração de glicose para $0,5 \mathrm{~g} \mathrm{~L}^{-1}$ (Etapa II), a constante $\mathrm{K}_{\mathrm{M}}$ foi de $1,1 \mathrm{~g} \mathrm{~L}^{-1}\left(\mathrm{R}^{2}\right.$ : 0,799), valor este 1,5 vezes superior ao registrado na Etapa I. Contudo, o pior resultado foi obtido na ausência do cossubstrato, $\mathrm{K}_{\mathrm{M}}$ de $14 \mathrm{~g} \mathrm{~L}^{-1}\left(\mathrm{R}^{2}\right.$ : 0,837), quase 20 vezes superior ao encontrado para a Etapa I. Estes resultados novamente confirmaram que a presença da glicose $\left(1 \mathrm{~g} \mathrm{~L}^{-1}\right)$ foi benéfica para a eficiência de remoção do corante pelos micro-organismos.

Radha et al. ${ }^{31}$ verificaram afinidade elevada de fungos pelo corante vermelho do congo $\left(0,02 \mathrm{~g} \mathrm{~L}^{-1}\right)$, na presença de glicose $\left(5 \mathrm{~g} \mathrm{~L}^{-1}\right) \mathrm{em}$ meio mineral. Utilizaram a espécie Phanerochaete chrysosporium imobilizada em esferas de alginato de sódio (2, 3, 4, 5 e $6 \mathrm{~mm}$ ), tendo obtido para a constante de afinidade $\left(\mathrm{K}_{\mathrm{M}}\right)$ valores variando de 0,203 a $0,253 \mathrm{~g} \mathrm{~L}^{-1}$, em função do tamanho das esferas. Estes valores foram de 3 a 4 vezes menores que os encontrado na presente pesquisa, nas Etapas I e II, porém é importante ressaltar que foi utilizada concentração 5 vezes menor de glicose $\left(1 \mathrm{~g} \mathrm{~L}^{-1}\right)$, de modo que ainda assim foram obtidos bons percentuais médios de remoção do vermelho do congo (95\%) e de matéria orgânica $(86 \%)$.

Em relação ao $\mathrm{pH}$, ao longo dos ciclos operacionais foi mantida a característica ácida do meio, o que foi observado em todas as Etapas 
de estudo, resultando em valor médio de 2,5 (Etapa I), 3,1 (Etapa II) e 4,1 (Etapa III).

A diminuição dos valores de $\mathrm{pH}$ no final dos ciclos operacionais está, possivelmente, relacionada à produção de ácidos orgânicos, devido à utilização das fontes de carbono pelos fungos. ${ }^{24}$ De fato, na Etapa I, quando houve maior remoção de corante do meio, estes valores foram menores, variando de 1,8 a 4 .

Wanderley ${ }^{32}$ estudou a remoção de vermelho do congo por Aspergillus niger em reatores em batelada, utilizando biomassa imobilizada e glicose $\left(1,0 \mathrm{~g} \mathrm{~L}^{-1}\right)$ como cossubstrato. Os reatores foram operados durante 25 dias e as maiores eficiências, quanto à remoção do corante ( 85 e $87 \%$ ), ocorreram quando o meio apresentou $\mathrm{pH}$ baixo $(3,2$ a 3,7$)$. $\mathrm{O}$ valor do $\mathrm{pH}$ nos reatores utilizados como controle foi superior a 7 e não foi observada remoção significativa de corante (12\%).

Michniewicz et al. ${ }^{33}$ obtiveram maior eficiência de remoção dos corantes têxteis azul ácido $62(125 \mu \mathrm{M})$ e $40(211 \mu \mathrm{M})$, azul reativo $81(124 \mu \mathrm{M})$ e preto direto $(92,25 \mu \mathrm{M})$ em meio aquoso, na condição de $\mathrm{pH}$ baixo, por enzimas lacases, produzidas pelo fungo Cerrena unicolor. Variaram o $\mathrm{pH}$ do meio de 2 a 7 e alcançaram maior produção de lacase em pH 3,5, correspondendo a $100 \%$ da atividade enzimática, a qual diminuiu drasticamente em $\mathrm{pH} 7$ para apenas $20 \%$ do valor inicial.

Os meios com valores baixo de $\mathrm{pH}$ são mais propícios aos fungos $^{24,34} \mathrm{e}$ grande número de enzimas secretadas por eles possuem sua atividade ótima em $\mathrm{pH}$ cujos valores se encontram na faixa ácida, sendo que a partir de 7 a atividade enzimática tende a diminuir, ${ }^{33}$ ocorrendo, consequentemente, a perda da eficiência da remoção do poluente.

No final da operação do reator, as análises de microscopia confirmaram a presença do Aspergillus niger AN400 e não foi observada contaminação do meio por micro-organismos alóctones. A contagem do número de colônias revelou concentração de esporos por $\mathrm{mL}$ de $8 \times 10^{4} \mathrm{UFC} \mathrm{mL}^{-1}$

\section{CONCLUSÕES}

$O$ reator em bateladas sequenciais com biomassa imobilizada da linhagem mutante Aspergillus niger AN400 apresentou boa eficiência quanto à diminuição da concentração de vermelho do congo (95\%) e de matéria orgânica carbonácea (86\%), obtidos na Etapa I.

Quando da adição da glicose na menor concentração estudada $(0,5$ $\left.\mathrm{g} \mathrm{L}^{-1}\right)$, a remoção de corante não diferiu da registrada sem a presença de glicose no meio, o que foi endossado pelos parâmetros cinéticos estimados, tanto pelo coeficiente de velocidade $\mathrm{k}_{1}\left(0,01 \mathrm{~h}^{-1}\right)$, como pela constante $\mathrm{K}_{\mathrm{M}}-1,1 \mathrm{e} 14 \mathrm{~g} \mathrm{~h}^{-1}$, respectivamente, nas Etapas II e III.

$\mathrm{O}$ uso da glicose como cossubstrato, na concentração de $1 \mathrm{~g} \mathrm{~L}^{-1}$ (Etapa I), resultou nos maiores valores estimados para a velocidade de remoção de corante $\left(\mathrm{k}_{1}: 0,025 \mathrm{~h}^{-1}\right)$ e para a constante de MichaelisMenten $\left(\mathrm{K}_{\mathrm{M}}\right)$, a qual foi de $0,7 \mathrm{~g} \mathrm{~L}^{-1}$. Porém, não houve mineralização completa do poluente, uma vez que, apesar de se ter constatado a eliminação da ligação azo e do anel naftaleno, o anel benzeno não foi efetivamente removido do meio.

Os resultados obtidos na pesquisa indicam a necessidade da continuidade dos estudos sobre a concentração ótima de glicose, bem como de outros tipos de cossubstrato, a fim de viabilizar a operação eficiente do sistema, prevendo a mineralização total do corante no efluente final.

\section{AGRADECIMENTOS}

Ao CNPq, pelo financiamento da pesquisa (Processo no 567552/2008, Edital Jovens Pesquisadores), e à FUNCAP pela concessão de duas bolsas de iniciação científica.

\section{REFERÊNCIAS}

1. Yang, Q.; Li, C.; Li, H.; Li, Y.; Yu, N.; Int. Biodet. Biodegradat. 2009, 63, 280.

2. Levin, L.; Papinutti, L.; Forchiassin, F.; Bioresour. Technol. 2004, 94, 169.

3. Ozfer, Y.; Asma, D.; Cing, S.; Process. Biochem. 2003, 38, 933.

4. Aksu, Z.; Dönmez, G.; Chemosphere 2003, 50, 1075.

5. Kunz, A.; Peralta-Zamora, P.; Moraes, S. G.; Durán, N.; Quim. Nova 2002, 25, 78.

6. Souza, K. V. de; Peralta-Zamora, P.; Zawadzki, S. F.; Quim. Nova 2008, 31,1145 .

7. Salgado, B. C. B.; Nogueira, M. I. C.; Rodrigues, K. A.; Sampaio, G. M. M. S.; Buarque, H. L. de B.; Araújo, R. dos S.; Eng. Sanit. Ambient. 2009, 14,1

8. Lucas, M.; Jeremias, P. F. P. T.; Andreaus, J.; Barcellos, I. O.; PeraltaZamora, P.; Quim. Nova 2008, 31, 1366.

9. Oliveira, D. M.; Leão, M. D.; Quim. Nova 2009, 32, 2282.

10. Khelifi, E.; Ayed L.; Bouallagui, H.; Touharni, Y.; Hamdi, M.; J. Hazard. Mater. 2009, 163, 1053

11. Barbosa, B. C. A.; Vidal, C. B.; Wanderley, C. R. P.; Marinho, G.; Rodrigues, K.; Conexões: Cienc. Tecnol. 2010, 3, 40

12. van der Zee, F.; Villaverde, S.; Water Res. 2005, 39, 1425.

13. Mustafa, I.; Sponza, T. D.; Bioresour. Technol. 2007, 34, 122.

14. Hassemer, M. E. N.; Senz, M. L.; Eng. Sanit. Ambient. 2002, 7, 30.

15. Souza, S. M. A. G. U.; Bonilla, K. A. S.; J. Hazard. Mater. 2010, 179, 35.

16. Rodrigues, K. A.; Tese de Doutorado, Universidade de São Paulo, Brasil, 2006.

17. El-Rahim, W. M. A.; El-Ardy, O. A. M.; Mohammad, F. H. A.; Desalination 2009, 249, 1206.

18. Parshetti, G. K.; Kalme, S. D.; Gomare, S. S.; Govindwar, S. P.; Bioresour. Technol. 2007, 98, 3638.

19. Spier, M. R.; Dissertação de Mestrado, Universidade Federal do Paraná, Brasil, 2005.

20. Fasanella, C. C.; Dissertação de Mestrado, Universidade de São Paulo, Brasil, 2008.

21. Franciscon, E.; Zille, A.; Guimaro, F. D.; Regagnin, C. de M.; Durrant, L. R.; Cavaco, P. A.; Int. Biodet. Biodegradat. 2009, 63, 280.

22. Singh, H.; Mycorremediation, Wiley: New Jersey, 2006.

23. APHA; Standard methods for the examination of water and wastewater, $21^{\text {th }}$ ed., American Health Association: Washington D. C., 2005.

24. Griffin, D. H.; Fungal physiology, $2^{\text {nd }}$ ed., Wiley: New York, 1994.

25. Steffan, S.; Bardi, L.; Marzona, M.; Environ. Int. 2005. 31, 127.

26. Sanghi, R.; Dixtit, A.; Verma, P.; Process Safety and Environ. Protect 2011, 89,15

27. Zhang, F. M.; Knapp, J. S.; Tapley, K. N.; Water Res. 1999, 33, 129.

28. Corrêa, C. A. R.; Dissertação de Mestrado, Universidade Federal de Ouro Preto, Brasil, 2009

29. Ali, N.; Lutfullah, I. G.; Hameed, A.; Ahmed. S.; World J. Microbiol. Biotechnol. 2008, 24, 1099.

30. Maliyekkal, S. M.; Rene, E. R.; Philip, L.; Swaminathan, T.; J. Hazard. Mater. 2004, 109, 201.

31. Radha, K. V.; Regupathi, I.; Arunagiri, A.; Murugesan, T.; Process. Biochem. 2005, 40, 3337.

32. Wanderley, C. R. P.; Dissertação de Mestrado, Universidade Federal do Ceará, Brasil, 2007

33. Michniewicz, A.; Ledakowicz, S.; Ullrich, R.; Hofrichter, M.; Dyes Pigm. 2008, 77, 295.

34. Assadi, M. M.; Jahangiri, M. R.; Desalination 2001, 14, 102. 